\title{
KATP channels in high glucose-induced rat mesangial cell proliferation and release of MMP-2 and fibronectin
}

\author{
BEI ZHANG, YONGQUAN SHI, JUNJIE ZOU, XIANGFANG CHEN, WEI TANG, FEI YE and ZHIMIN LIU \\ Department of Endocrinology, Shanghai Changzheng Hospital, Shanghai 200003, P.R. China
}

Received January 23, 2017; Accepted March 1, 2017

DOI: $10.3892 / \mathrm{etm} .2017 .4458$

\begin{abstract}
ATP-sensitive potassium (KATP) channels are well characterized in cardiac, pancreatic and many other muscle cells. The purpose of this study was to determine if KATP channels play a role in diabetic nephropathy (DN). In the present study, functional expression of the KATP channel was examined in rat mesangial cells with or without high glucose (HG) stimulation. The mesangial cell proliferation and the release of matrix metalloproteinase (MMP)-2 and fibronectin in response to high glucose with a selective opener of KATP (diazoxide, DZX), or with a selective inhibitor of KATP (5-hydroxydecanoate, 5-HD) were also measured. The cell proliferation was observed using Cell Counting Kit- 8 assay, and the mRNA expressions of KATP subunit, including Kir6.1, Kir6.2, sulfonylurea receptor 1 (SUR1), SUR2A and SUR2B, were assessed using quantitative real-time PCR. MMP-2 and fibronectin release was measured by ELISA. The present study clarified expression of SUR subunit of KATP in plasma. HG treatment could cause increased cell proliferation and release of MMP-2 and fibronectin in a dose-dependent manner. HG also significantly decreased the expression of Kir6.1, SUR2A and SUR2B. Pretreatment of DZX markedly decreased the expression of SUR1, SUR2A and SUR2B, but had no effect on Kir6.1 expression compared with HG alone, while these changes were inhibited by 5-HD pretreatment. Moreover, DZX also inhibited cell proliferation and release of MMP-2 and fibronectin in HG-induced rat mesangial cells, and that was corrected by 5-HD. These data suggest that HG stimulates mesangial cell proliferation and cellular matrix release via inhibiting KATP channel activity, leading us to propose that KATP channel dysfunction may be involved in the development of DN.
\end{abstract}

Correspondence to: Dr Yongquan Shi, Department of Endocrinology, Shanghai Changzheng Hospital, 415 Fengyang Road, Huangpu, Shanghai 200003, P.R. China

E-mail: s7m812@163.com

Key words: high glucose, KATP, proliferation, MMP-2, fibronectin

\section{Introduction}

Diabetic nephropathy (DN), one of the most serious microvascular complications of diabetes mellitus, is the leading cause of end-stage renal disease in developed countries and major cause of diabetes-related death $(1,2)$. It is characterized by kidney hypertrophy, glomerulus and tubular basement membrane thickening, tubular interstitial fibrosis and arteriosclerosis $(3,4)$, which is largely due to mesangial cell proliferation, extracellular matrix (ECM) deposition. Therefore, searching for effective methods of inhibiting mesangial cell proliferation and ECM accumulation may be of great clinical importance for intervention in DN.

Hyperglycemia plays a central role in the development and progression of DN (5). High glucose (HG) promotes mesangial cell proliferation and fibronectin expression in vitro. HG induces renal mesangial cell proliferation and fibronectin expression through JNK/nuclear factor (NF)- $\mathrm{KB} / \mathrm{NADPH}$ oxidase/ROS pathway (6). HG induced mesangial cell proliferation and arrested cell cycle progress through upregulation of p-p38MAPK (7). Mesangial cells also play a role in the synthesis, as well as the degradation of the ECM, which is mediated by proteinases such as matrix metalloproteinases (MMPs), including type IV collagen, fibronectin and proteoglycans (8). Increased levels of both MMP-2 and MMP-9 have been demonstrated in serum from patients with type 1 diabetes (9), and the level of urine MMP-9 was correlated with the degree of albuminuria (10).

ATP-sensitive potassium (KATP) channels were first identified in cardiac cell (11), inhibited by intracellular ATP and activated by $\mathrm{MgADP}(12)$, and coupled cellular energy status to electrical activity playing a critical role in regulating numerous cellular functions, such as cardiac preconditioning, vasodilatation, neuroprotection (13) as well as glucose homeostasis by regulating insulin secretion (14). High glucose conditions have led to the recruitment of KATP channels to the $\beta$-cell plasma membrane in $\mathrm{Ca}^{2+}$ and PKA-dependent manner, resulting in an increase in KATP currents (15), whereas a protein kinase C activator facilitated endocytic trafficking of KATP, resulting in decreased KATP currents (16). At molecular level, the KATP channel is composed of subunits from a combination of inwardly rectifying $\mathrm{K}^{+}$channels (Kir6.1 or Kir6.2) and sulfonylurea receptors (SUR1, SUR2A and SUR2B). KATP channel closure occur by binding to the pore-forming subunit Kir6.2, yet activate channel opening by interacting with the 
regulatory subunit SUR in a $\mathrm{Mg}^{2+}$-dependent manner (17). It is believed that different Kir6 combine with different SUR to form the various native KATP channels (18). Different KATP channels exhibit different pharmacological profiles dictated by the SUR subtypes they are composed of. However, the existence subtypes and role of KATP channels in DN is still not well defined.

In the present study, we investigated the effects of $\mathrm{HG}$ on cell proliferation and release of MMP-2 and FN in rat mesangial cells, and elucidated the role of KATP channels in HG-induced DN.

\section{Materials and methods}

Isolation and culture of mesangial cells. The experiments were performed in accordance with the Animal Ethics Committee of the Second Military Medical University. Primary rat mesangial cells were harvested from male Sprague-Dawley rat (150-200 g) (the Second Military Medical University Animal Center, Shanghai, China) by filtration with ice-cold $0.9 \% \mathrm{NaCl}$ solution through a 200 -, 120 - and $80-\mu \mathrm{m}$ nylon mesh. Those retained on the sieve were collected, washed by centrifugation $\left(4^{\circ} \mathrm{C} ; 800 \mathrm{x} \mathrm{g}\right.$; $6 \mathrm{~min}$ ), and incubated with $4 \mathrm{mg} / \mathrm{ml}$ collagenase type IV for $10 \mathrm{~min}$ at $37^{\circ} \mathrm{C}$ under constant, gentle shaking. Mesangial cells were placed on $25-\mathrm{cm}^{2}$ culture flasks in Dulbecco's modified Eagle's medium (DMEM)/F12 (Hyclone-Thermo Fisher Scientific, Inc., San Jose, CA, USA) at $37^{\circ} \mathrm{C}$ in humidified $5 \% \mathrm{CO}_{2}-95 \%$ air. The culture media was not changed for the first 7 days. Thereafter, the medium was changed every other day until confluence and passages 11 to 17 were used in this study. Mesangial cells at $\sim 80 \%$ confluence were cultured in $1 \%$ fetal bovine serum (FBS) DMEM for $24 \mathrm{~h}$ for synchronization, and then were exposed to low glucose $(5.6 \mathrm{mM})$, high glucose $(30 \mathrm{mM})$, with or without the pretreatment of diazoxide (DZX) $(50 \mu \mathrm{M})$ or 5-hydroxydecanoate (5-HD) $(200 \mu \mathrm{M})$. The cell phenotypes were determined by light microscopy.

Quantitative real-time PCR. Total RNA was extracted and purified from $1 \times 10^{6}$ cells using QIAzol reagent (Qiagen, Valencia, CA, USA). Total RNA ( $1 \mu \mathrm{g})$ was reverse-transcribed into cDNA according to the instructions of PrimeScript RT Master Mix (Takara Bio Inc., Shiga, Japan). Real-time PCR was performed to measure the mRNA levels of Kir6.1, Kir6.2, SUR1, SUR2A, SUR2B and GAPDH, an internal control, for each sample in separate wells in duplicate on an ABI-7300 Sequence Detection system using $2 \mu \mathrm{l}$ of cDNA, $300 \mathrm{nM}$ primers and SYBR-Green PCR Master Mix (all from Applied Biosystems, Foster City, CA, USA). The primers were: Kir6.1 forward, 5'-TTGGAGGGAGAATGA TGAC-3' and reverse, 5'-CATTACGGACCGCAATTAC-3'; Kir6.2 forward, 5'-CCACGACAGGATAAGTTTACC-3' and reverse, 5'-TCTCAGTGTTTGCCCAATG-3'; SUR1 forward, 5'-GGTTCGGTCCACTGTCAAG-3' and reverse, 5'-GTTGT CAGCGTCTCCATCC-3'; SUR2A forward, 5'-GGAGCAAT CCAGACCAAGAT-3' and reverse, 5'-AGCCAGCAGATGAT GACA-3'; SUR2B forward, 5'-ACCTGCTCCAGCACAA GAAT-3' and reverse, 5'-TCTCTTCATCACATTGACC AGG-3'; GAPDH forward, 5'-GTCGGTGTGAACGGAT
TTG-3' and reverse, 5'-TCCCATTCTCAGCCTTGAC-3'. The relative gene expression levels are presented as $2^{-\Delta \Delta C q}(19)$.

Subcellular localization of SUR subunit of KATP. Cell slices were washed three times with phosphate-buffered saline (PBS) and fixed with $4 \%$ methanol for $30 \mathrm{~min}$ prior to PBS washed twice, and then cell were cultured in serum-free DMEM medium containing $1 \mu \mathrm{M}$ BODIPY-glibenclamide at $37^{\circ} \mathrm{C}$ for $30 \mathrm{~min}$ in the dark and $5 \mu \mathrm{M}$ DiIC18(3) at $37^{\circ} \mathrm{C}$ for $10 \mathrm{~min}$ in the dark. After incubation, cells were washed three times with PBS and DAPI Fluoromount-G was added at $37^{\circ} \mathrm{C}$ for $5 \mathrm{~min}$ in the dark. Laser scanning confocal microscopy was used to determine the fluorescence signal, magnification, x600.

Cell proliferation assay. Cells were seeded at $10^{4}$ cells/well in 96-well plates. After 24-h incubation, the media was removed and replaced with serum-free medium for 24-h incubation. Plates were then treated with high glucose $(10,20,30$ or $40 \mathrm{mM}$ ) for another 12 or $24 \mathrm{~h}$. Then $10-\mu \mathrm{l}$ Cell Counting Kit-8 (CCK-8) solution was added to each well and incubation continued at $37^{\circ} \mathrm{C}$ for another $1 \mathrm{~h}$. Cell proliferation was determined by scanning with a microplate reader (model 680; Bio-Rad Laboratories, Inc., Hercules, CA, USA) at $450 \mathrm{~nm}$.

ELISA. Cell culture supernatants from different treatment groups were harvested and centrifuged at $800 \mathrm{x} \mathrm{g}$ for $20 \mathrm{~min}$. After centrifugation, the supernatants were then assayed for MMP-2 and fibronectin using the enzyme-linked immunosorbent assay (ELISA) kits (Wuhan Boster Biological Engineering Co., Ltd., Wuhan, China). The absorbance was read at $450 \mathrm{~nm}$ with an ELx800 microplate (BioTek Instruments, Inc., Winooski, VT, USA).

Statistical analysis. All investigations were performed in triplicate. The data were assessed by SPSS version 11.5 (IBM SPSS, Armonk, NY, USA). All values were expressed as mean \pm SD. Statistical analyses of data were performed by one-way analysis of variance (ANOVA) and Student's t-test. $\mathrm{P}<0.05$ was considered to indicate a statistically significant difference.

\section{Results}

KATP subunit expression and subcellular localization. To investigate the role of KATP in mesangial cells, the expression of KATP subunit, including Kir6.1, Kir6.2, SUR1, SUR2A and SUR2B, was measured by quantitative real-time PCR. As shown in Fig. 1A, in all detected KATP subunit, the highest mRNA expression was detected in Kir6.1 and the lowest mRNA expression was detected in SUR1. Moreover, the expression of SUR in plasma membranes was also found using a laser scanning confocal microscopy incubated with BODIPY-glibenclamide and DiIC18(3) (Fig. 1B).

High glucose increases mesangial cell proliferation and release of MMP-2 and fibronectin. After different concentrations of high glucose (HG, 10, 20, 30 or $40 \mathrm{mM}$ ) treatment in mesangial cells, the cell proliferation was measured by CCK-8 assay. As shown in Fig. 2A, HG with concentration 
A

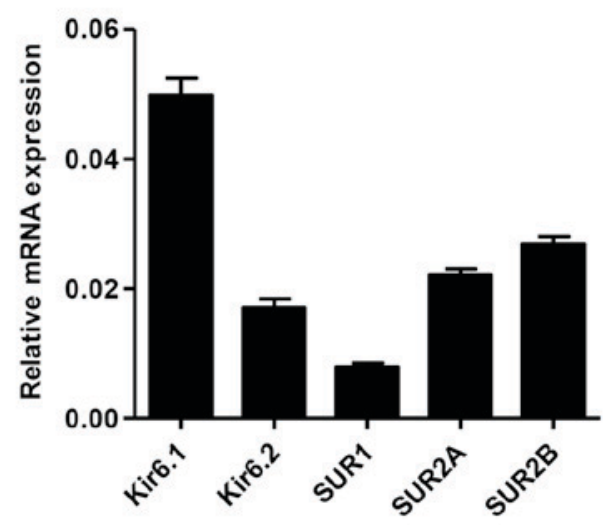

B
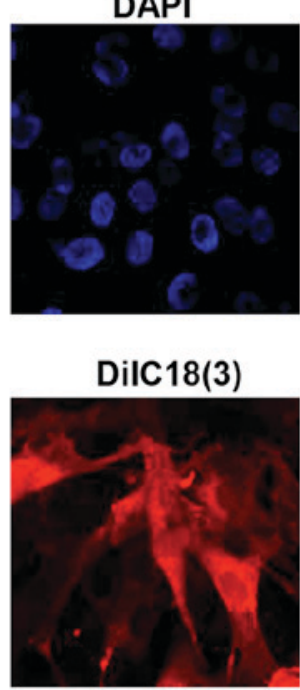

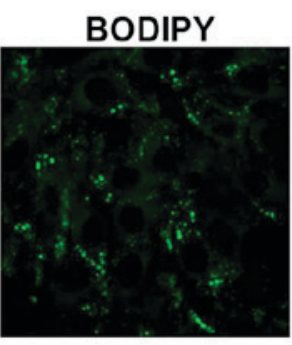

Merge

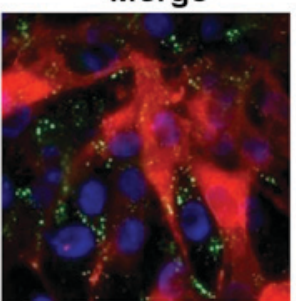

Figure 1. KATP subunit expression and subcellular localization. (A) The mRNA expression of KATP subunit, including Kir6.1, Kir6.2, SUR1, SUR2A and SUR2B, was measured by quantitative real-time PCR. (B) The subcellular localization of KATP subunit SUR was measured by BODIPY-glibenclamide and 5- $\mu \mathrm{M}$ DiIC18(3). KATP, ATP-sensitive potassium.

A

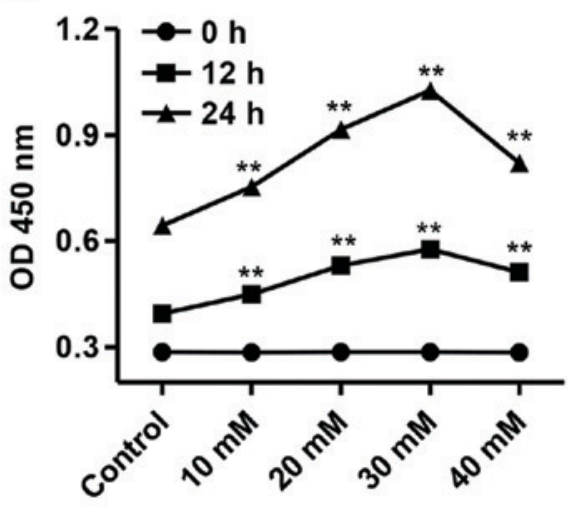

C

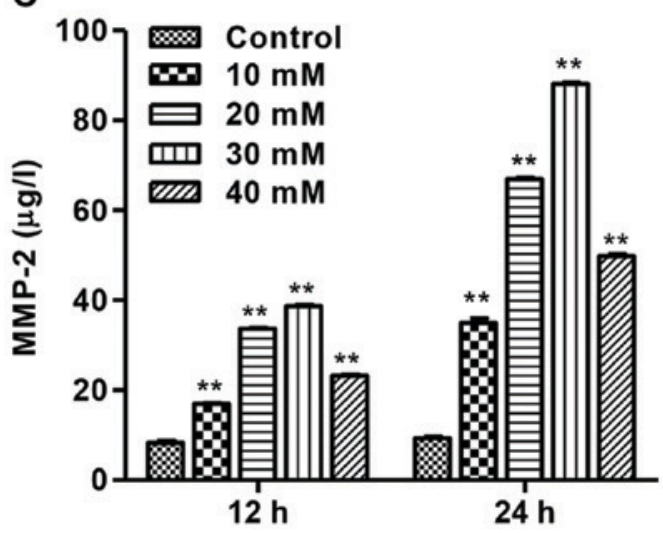

B

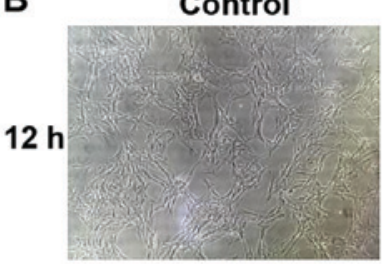

Control

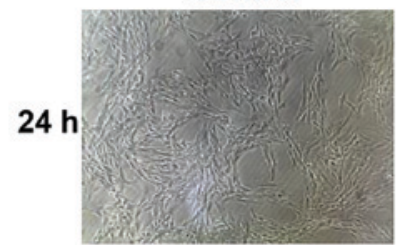

D

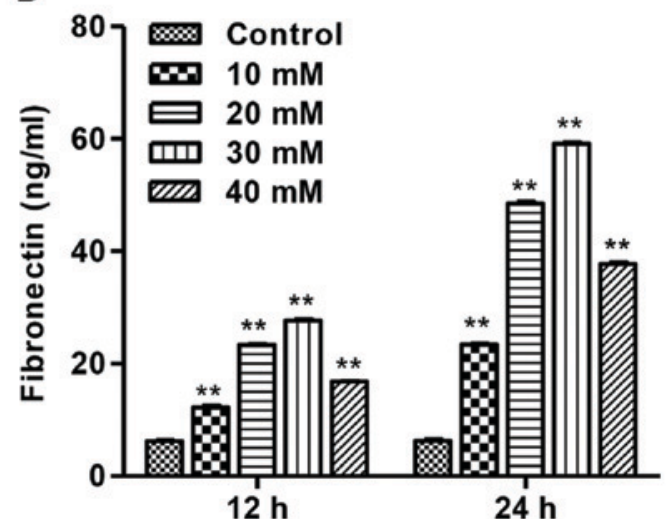

Figure 2. High glucose promotes mesangial cell proliferation and production of MMP-2 and fibronectin. Rat mesangial cells were cultured with different doses of high glucose (HG, 10, 20,30 or $40 \mathrm{mM}$ ) for 12 or $24 \mathrm{~h}$. (A and B) The cell proliferation was measured by CCK-8 assay. (C and D) The production of MMP-2 and fibronectin was measured by ELISA. ${ }^{* *} \mathrm{P}<0.01$ compared with the control. MMP, matrix metalloproteinase.

ranges from 10 to $30 \mathrm{mM}$ significantly increased mesangial cell proliferation in a dose-dependent manner in 12 and $24 \mathrm{~h}$, while $40 \mathrm{mM} \mathrm{HG}$ inhibits mesangial cell proliferation, compared with control mesangial cells. The phenotypes of mesangial cells in response to $30 \mathrm{mM} \mathrm{HG}$ for 12 and $24 \mathrm{~h}$ are shown in Fig. 2B. 
A

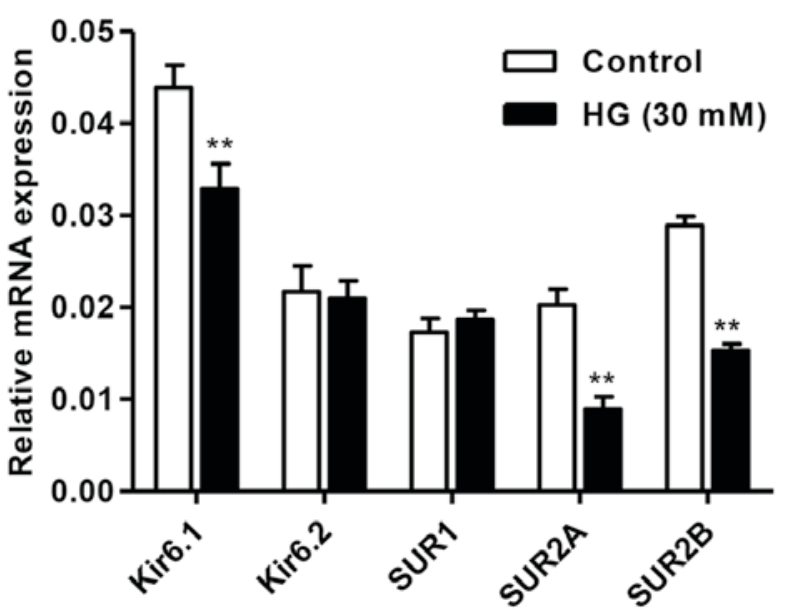

B

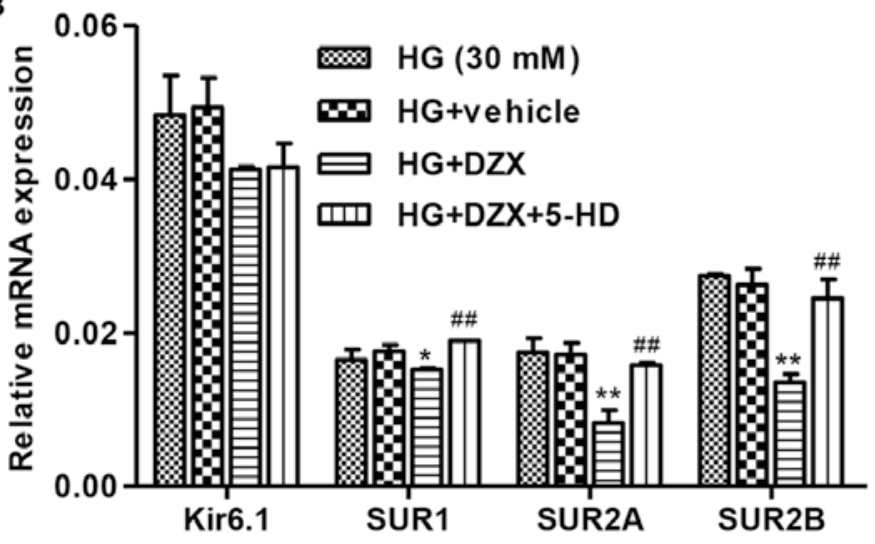

Figure 3. DZX inhibits HG-induced KATP subunit expression. Rat mesangial cells were cultured with $30 \mathrm{mM}$ HG for $24 \mathrm{~h}$. (A) The mRNA expression of KATP subunit, including Kir6.1, Kir6.2, SUR1, SUR2A and SUR2B, was measured by quantitative real-time PCR. Rat mesangial cells were cultured with DZX or/and 5-HD prior to $30 \mathrm{mM}$ HG for $24 \mathrm{~h}$. ${ }^{* *} \mathrm{P}<0.01$ compared with the control. (B) The mRNA expression of KATP subunit, including Kir6.1, SUR1, SUR2A and SUR2B, was measured by quantitative real-time PCR. ${ }^{*} \mathrm{P}<0.05,{ }^{* * *} \mathrm{P}<0.01$ compared with $\mathrm{HG}$; ${ }^{\# \#} \mathrm{P}<0.01$ compared with HG+DZX. DZX, diazoxide; KATP, ATP-sensitive potassium.

A

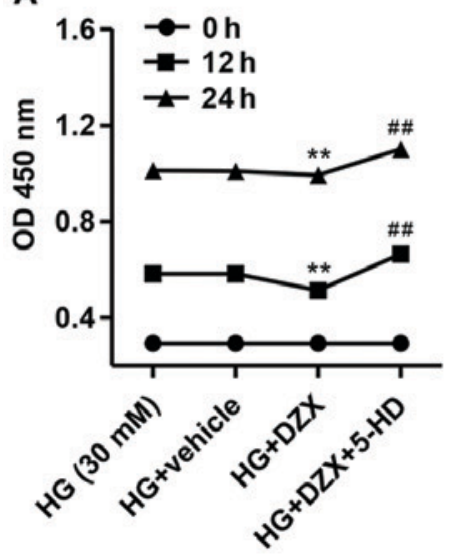

B

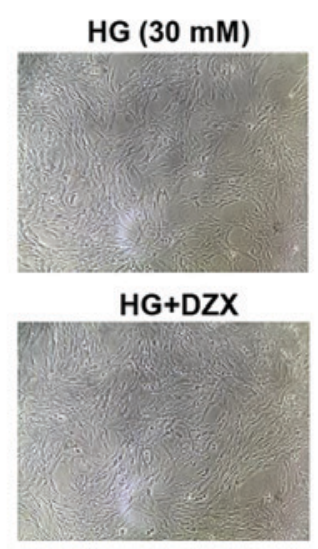

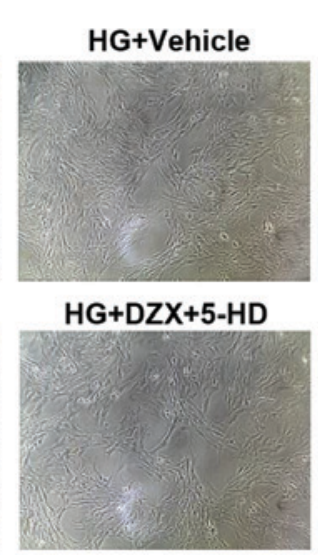

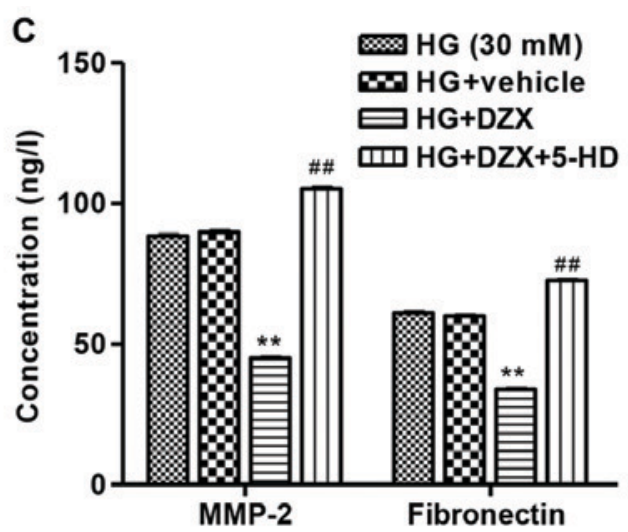

Figure 4. DZX inhibits HG-induced mesangial cell proliferation and production of MMP-2 and fibronectin. Rat mesangial cells were cultured with DZX or/and 5-HD prior to $30 \mathrm{mM} \mathrm{HG}$ for 12 or $24 \mathrm{~h}$. (A and B) The cell proliferation was measured by CCK-8 assay. (C) The production of MMP-2 and fibronectin was measured by ELISA. ${ }^{* *} \mathrm{P}<0.01$ compared with HG; ${ }^{\# \#} \mathrm{P}<0.01$ compared with HG+DZX. DZX, diazoxide; MMP, matrix metalloproteinase.

Furthermore, to investigate the effect of $\mathrm{HG}$ on matrix components, the production of MMP-2 and fibronectin was measured by ELISA. Our results showed that HG with concentration ranges from 10 to $30 \mathrm{mM}$ significantly increased MMP-2 and fibronectin production in a dose-dependent manner, while $40 \mathrm{mM}$ HG inhibits MMP-2 and fibronectin production, compared with control mesangial cells (Fig. 2C and D).

DXZ inhibits high glucose-induced KATP subunit expression. To investigate the effect of HG on KATP subunit, the expression of Kir6.1, Kir6.2, SUR1, SUR2A and SUR2B was detected. We found that $30 \mathrm{mM} \mathrm{HG}$ significantly decreased the mRNA expression of Kir6.1, SUR2A and SUR2B, but had no effect on Kir6.2 and SUR1 expression compared with controls (Fig. 3A). These results suggest that HG induced mesangial cell proliferation and MMP-2 and fibronectin production may be through inhibiting KATP channel activity. Therefore, a selective opener of KATP (DZX) and a selective inhibitor of KATP (5-HD) were also introduced in our study. As shown in Fig. 3B, DZX significantly decreased the mRNA expression of SUR1, SUR2A and SUR2B in HG-induced mesangial cells. However, the changes in SUR1, SUR2A and SUR2B mRNA expression were significantly reversed by 5-HD. Whereas, DZX or 5-HD treatment had no effect on the mRNA expression of Kir6.2 KATP subunit (data not shown).

DXZ inhibits high glucose-induced mesangial cell proliferation and MMP-2 and fibronectin production. As shown in Fig. 4A and B, DZX significantly decreased mesangial cell proliferation, while 5-HD increased mesangial cell proliferation under HD condition at 12 and $24 \mathrm{~h}$ with DZX pretreatment. Additionally, DZX significantly decreased the production of MMP-2 and fibronectin in HG-induced mesangial cells (Fig. 4C). However, the changes in MMP-2 and fibronectin production were significantly reversed by $5-\mathrm{HD}$. 


\section{Discussion}

The KATP channel serves as a metabolic sensor, coupling cellular metabolism to electrical activity in a wide range of tissues. Opening of KATP channels under conditions of low metabolism leads to membrane hyperpolarization and switches off cellular functions, and close when metabolism increases, producing a membrane depolarization that leads to cellular responses such as hormonal secretion, neurotransmitter release and contraction, conversely (14). A previous result has indicated that KATP channels seem to play an essential role in murine myometrial motility via activation of SUR2B and Kir6.2 (20). Moreover, the main KATP channel in cardiomyocytes is composed of Kir6.2/SUR2A, and the primary role of KATP channels in heart is cardioprotection under metabolic stress, such ischemia, anoxia or metabolic inhibition $(21,22)$. Despite the large amount of evidence confirming the role of KATP channels in cardioprotection during metabolic stress, the SUR $1^{-/}$and SUR2 ${ }^{-/}$knockout mice were found to be more tolerant of global ischemia-reperfusion than control mice $(23,24)$. However, the roles of KATP channels in HG-induced DN are not elucidated. In the present study, we found that activating KATP channels significantly suppressed HG-induced cell proliferation and release of MMP-2 and fibronectin in cultured mesangial cells.

Several clinical studies have demonstrated that elevated blood glucose level was a risk for the development of microvascular complications of diabetes, including DN. Increased mesangial cell proliferation and excessive accumulation of ECM proteins synthesized by mesangial cells are major pathologic features in the early stage of DN $(25,26)$. Our results showed that HG enhanced mesangial cell proliferation and release of MMP-2 and fibronectin in a dose-dependent manner range from 10 to $30 \mathrm{mM}$. As one of the most important ECM proteins, glucose-induced fibronectin expression in MCs results in the accelerated progression of glomerulosclerosis (27). Previous studies have implied that MMPs play an important role in regulating physiological homeostasis and pathological disorders of the kidney through modulating the decomposition of ECM components, including fibronectin (28).

Most studies have focused on direct regulation, such as changes in the open probability or the ATP sensitivity of the channels (29), but little is known about how channel numbers at the surface membrane are regulated. Our results demonstrated that all the subunits of KATP were expressed in rat mesangial cell, and the SUR subunit was observed in plasma membranes using a laser scanning confocal microscopy incubated with BODIPY-glibenclamide and DiIC18 (3). A previous study demonstrated that KATP channels play a role in the cardioprotective effects of $\mathrm{H}_{2} \mathrm{~S}$ against $\mathrm{HG}$-induced injury, in which treatment of the cells with HG markedly decreased the expression level of KATP channels (30). Our results showed that the expression of KATP subunits, including Kir6.1, SUR2A and SUR2B, was also decreased by HG stimulation. Thus, we hypothesized that the inhibition of KATP channels is a critical mechanism which underlies HG-induced renal injury. To confirm this hypothesis, we observed the influence of KATP channel activation on HG-induced injury. One promising strategy is the use of DZX (a mitochondrial KATP channel opener) and a mitochondrial KATP channel blocker (5-HD). We found that DZX pretreatment inhibited HG-induced SUR1, SUR2A and SUR2B expression and 5-HD pretreatment inhibited DZX-induced decreased expression of SUR1, SUR2A and SUR2B. Importantly, DZX decreased cell proliferation and the release of MMP-2 and fibronectin, while 5-HD inhibited the effects of DZX in HG-induced mesangial cells.

In conclusion, the present study provides novel evidence that the impairment of KATP channels is associated with HG-induced multiple renal injuries, including increased mesangial cell proliferation and excessive accumulation of ECM proteins. Taken together, we could conclude that one of the molecular mechanisms involved in renal protective effects was activation of KATP channels. Our results also provided a potential target in treatment of DN.

\section{References}

1. Aghadavod E, Khodadadi S, Baradaran A, Nasri P, Bahmani M and Rafieian-Kopaei M: Role of oxidative stress and inflammatory factors in diabetic kidney disease. Iran J Kidney Dis 10: 337-343, 2016.

2. John S: Complication in diabetic nephropathy. Diabetes Metab Syndr 10: 247-249, 2016.

3. Kolset SO, Reinholt FP and Jenssen T: Diabetic nephropathy and extracellular matrix. J Histochem Cytochem 60: 976-986, 2012

4. Ruster C and Wolf G: The role of chemokines and chemokine receptors in diabetic nephropathy. Front Biosci 13: 944-955, 2008.

5. Kikkawa R, Koya D and Haneda M: Progression of diabetic nephropathy. Am J Kidney Dis 41 (Suppl 1): S19-S21, 2003.

6. Zhang L, Pang S, Deng B, Qian L, Chen J, Zou J, Zheng J, Yang L, Zhang C, Chen X, et al: High glucose induces renal mesangial cell proliferation and fibronectin expression through $\mathrm{JNK} / \mathrm{NF}-\kappa \mathrm{B} / \mathrm{NADPH}$ oxidase/ROS pathway, which is inhibited by resveratrol. Int J Biochem Cell Biol 44: 629-638, 2012.

7. Li X, Liu W, Wang Q, Liu P, Deng Y, Lan T, Zhang X, Qiu B, Ning $\mathrm{H}$ and Huang $\mathrm{H}$ : Emodin suppresses cell proliferation and fibronectin expression via p38MAPK pathway in rat mesangial cells cultured under high glucose. Mol Cell Endocrinol 307: 157-162, 2009.

8. Tan RJ and Liu Y: Matrix metalloproteinases in kidney homeostasis and diseases. Am J Physiol Renal Physiol 302: F1351-F1361, 2012.

9. Gharagozlian S, Svennevig K, Bangstad HJ, Winberg JO and Kolset SO: Matrix metalloproteinases in subjects with type 1 diabetes. BMC Clin Pathol 9: 7, 2009.

10. Thompson J, Wilson P, Brandewie K, Taneja D, Schaefer L, Mitchell B and Tannock LR: Renal accumulation of biglycan and lipid retention accelerates diabetic nephropathy. Am J Pathol 179: 1179-1187, 2011.

11. Burke MA, Mutharasan RK and Ardehali H: The sulfonylurea receptor, an atypical ATP-binding cassette protein, and its regulation of the KATP channel. Circ Res 102: 164-176, 2008.

12. Wheeler A, Wang C, Yang K, Fang K, Davis K, Styer AM, Mirshahi U, Moreau C, Revilloud J, Vivaudou M, et al: Coassembly of different sulfonylurea receptor subtypes extends the phenotypic diversity of ATP-sensitive potassium (KATP) channels. Mol Pharmacol 74: 1333-1344, 2008.

13. Teramoto N, Zhu HL, Shibata A, Aishima M, Walsh EJ, Nagao $\mathrm{M}$ and Cole WC: ATP-sensitive $\mathrm{K}^{+}$channels in pig urethral smooth muscle cells are heteromultimers of Kir6.1 and Kir6.2. Am J Physiol Renal Physiol 296: F107-F117, 2009.

14. McTaggart JS, Clark RH and Ashcroft FM: The role of the KATP channel in glucose homeostasis in health and disease: more than meets the islet. J Physiol 588: 3201-3209, 2010.

15. Yang SN, Wenna ND, Yu J, Yang G, Qiu H, Yu L, Juntti-Berggren L, Köhler M and Berggren PO: Glucose recruits $\mathrm{K}(\mathrm{ATP})$ channels via non-insulin-containing dense-core granules. Cell Metab 6: 217-228, 2007.

16. Hu K, Huang CS, Jan YN and Jan LY: ATP-sensitive potassium channel traffic regulation by adenosine and protein kinase $\mathrm{C}$. Neuron 38: 417-432, 2003. 
17. Chen PC, Kryukova YN and Shyng SL: Leptin regulates KATP channel trafficking in pancreatic $\beta$-cells by a signaling mechanism involving AMP-activated protein kinase (AMPK) and cAMP-dependent protein kinase (PKA). J Biol Chem 288: 34098-34109, 2013.

18. Masia R, Enkvetchakul D and Nichols CG: Differential nucleotide regulation of KATP channels by SUR1 and SUR2A. J Mol Cell Cardiol 39: 491-501, 2005.

19. Livak KJ and Schmittgen TD: Analysis of relative gene expression data using real-time quantitative PCR and the $2 \Delta \Delta \mathrm{Ct}$ method. Methods 25: 402-408, 2001.

20. Hong SH, Kyeong KS, Kim CH, Kim YC, Choi W, Yoo RY, Kim HS, Park YJ, Ji IW, Jeong EH, et al: Regulation of myometrial contraction by ATP-sensitive potassium (KATP) channel via activation of SUR2B and Kir 6.2 in mouse. J Vet Med Sci 78: 1153-1159, 2016

21. Zhang H, Flagg TP and Nichols CG: Cardiac sarcolemmal K(ATP) channels: latest twists in a questing tale! J Mol Cell Cardiol 48: 71-75, 2010.

22. Pu JL, Ye B, Kroboth SL, McNally EM, Makielski JC and Shi NQ: Cardiac sulfonylurea receptor short form-based channels confer a glibenclamide-insensitive KATP activity. J Mol Cell Cardiol 44: 188-200, 2008.

23. Elrod JW, Harrell M, Flagg TP, Gundewar S, Magnuson MA, Nichols CG, Coetzee WA and Lefer DJ: Role of sulfonylurea receptor type 1 subunits of ATP-sensitive potassium channels in myocardial ischemia/reperfusion injury. Circulation 117: $1405-1413,2008$
24. Lefer DJ, Nichols CG and Coetzee WA: Sulfonylurea receptor 1 subunits of ATP-sensitive potassium channels and myocardial ischemia/reperfusion injury. Trends Cardiovasc Med 19: 61-67, 2009

25. Yuan P, Xue H, Zhou L, Qu L, Li C, Wang Z, Ni J, Yu C, Yao T, Huang Y, et al: Rescue of mesangial cells from high glucose-induced over-proliferation and extracellular matrix secretion by hydrogen sulfide. Nephrol Dial Transplant 26: 2119-2126, 2011.

26. Rysz J, Banach M, Stolarek RA, Pasnik J, Cialkowska-Rysz A, Koktysz R, Piechota M and Baj Z: Serum matrix metalloproteinases MMP-2 and MMP-9 and metalloproteinase tissue inhibitors TIMP-1 and TIMP-2 in diabetic nephropathy. J Nephrol 20: 444-452, 2007.

27. Wang J, Huang H, Liu P, Tang F, Qin J, Huang W, Chen F, Guo F, Liu W and Yang B: Inhibition of phosphorylation of p38 MAPK involved in the protection of nephropathy by emodin in diabetic rats. Eur J Pharmacol 553: 297-303, 2006

28. Hopps E and Caimi G: Matrix metalloproteinases in metabolic syndrome. Eur J Intern Med 23: 99-104, 2012.

29. Tarasov AI, Girard CA and Ashcroft FM: ATP sensitivity of the ATP-sensitive $\mathrm{K}^{+}$channel in intact and permeabilized pancreatic beta-cells. Diabetes 55: 2446-2454, 2006.

30. Liang W, Chen J, Mo L, Ke X, Zhang W, Zheng D, Pan W, Wu S, Feng J, Song M, et al: ATP-sensitive $\mathrm{K}^{+}$channels contribute to the protective effects of exogenous hydrogen sulfide against high glucose-induced injury in H9c2 cardiac cells. Int J Mol Med 37: 763-772, 2016 